\title{
Psicologia e os Contextos Socio-Político-Cultural e das Políticas Sociais no Século XXI
}

Psychology And Socio-Political-Cultural And Social Policies Contexts In The XXI Century

Psicología Y Los Contextos Socio-Político-Cultural Y De Las Políticas Sociales En El Siglo XXI
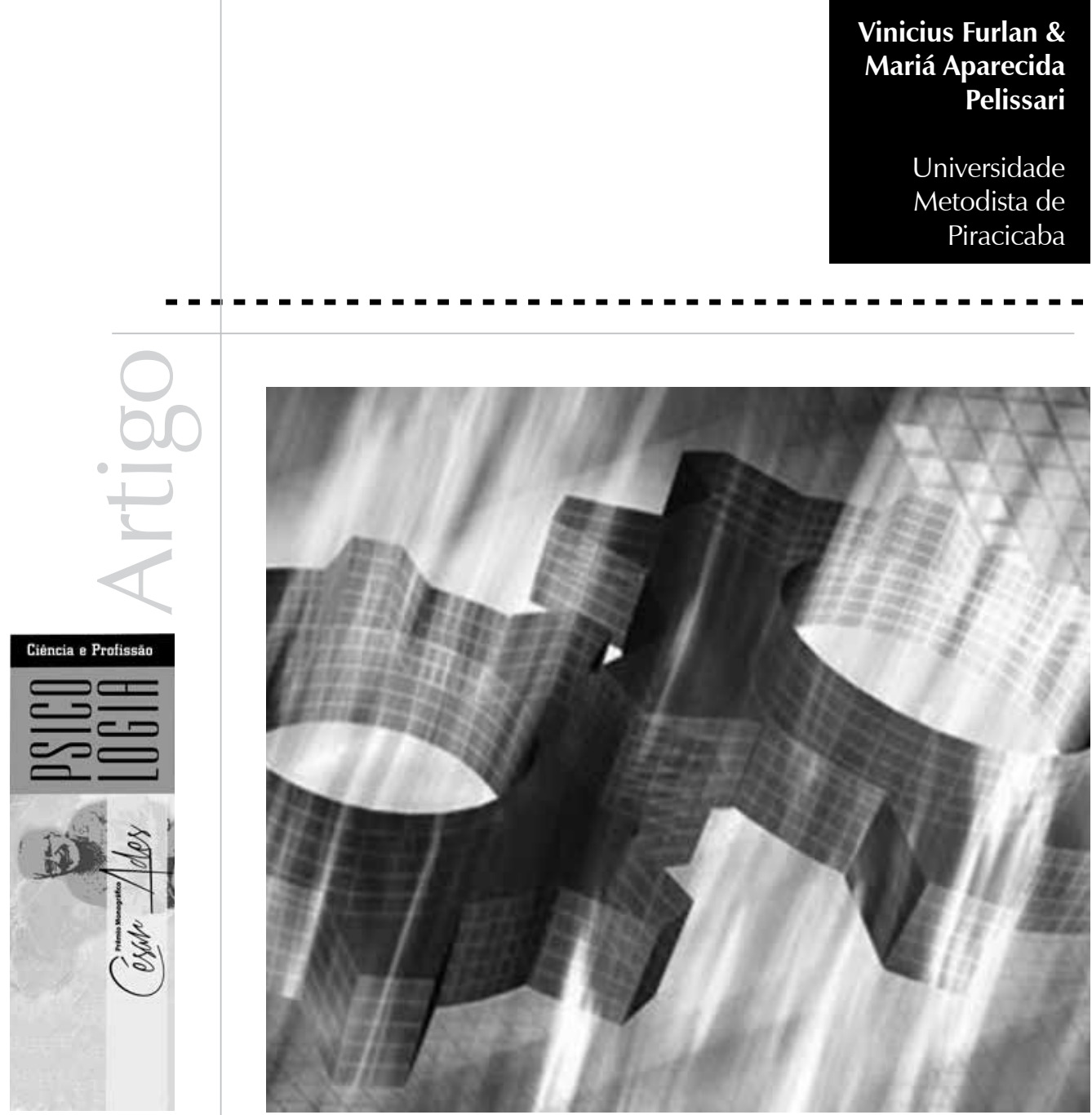
Resumo: O presente texto constitui uma discussão realizada a partir de uma pesquisa que visou a identificar os temas e os contextos tratados nos artigos da revista Psicologia e Sociedade e nos anais dos Encontros Nacionais da ABRAPSO, ambos publicados por essa associação, no período que recobre de 2000 a 2010. A partir dos dados levantados, discutimos a articulação dos contextos socio-político-cultural e o das políticas e projetos sociais, em que o primeiro revela grande incidência e o segundo, baixa incidência nas publicações. Em que pese uma grande diferença na publicação de trabalhos que discutem esses contextos, percebe-se um aumento gradativo, de um ano para outro, nas produções que se inserem e que refletem acerca do contexto das políticas e projetos sociais. Esses dados, portanto, além de outros fatores, revelam o compromisso da Psicologia em adentrar os espaços referentes à construção de políticas públicas e projetos sociais com vistas a garantir a promoção e a defesa dos direitos humanos e de uma sociedade digna de ser vivida, ou seja, o interesse na construção do bem comum.

Palavras-chave: Projeto social. Política social. Psicologia. Direitos humanos.

Abstract: This text represents a discussion held from a survey that aimed to identify the issues and the contexts in the journal Psychology and Society and in the proceedings of the National Meetings of ABRAPSO, both published by the association, which cover the period from 2000 to 2010. From the data collected, it discusses the articulation of socio-political-cultural and social policies and projects context, in which the first reveals a high incidence and the second a low incidence in publications. Despite there is a big difference in the publication of papers that discuss these contexts, one perceives a gradual increase from one year to another in productions that belong to and that reflect the context of policies and social projects. These data, therefore, in addition to other factors, reveal the commitment of psychology in entering the spaces for the construction of public policies and social projects in order to ensure the promotion and defense of human rights and a society in which it is worth living, ie, interest in the construction of the common welfare. Keywords: Social project. Social policy. Psychology. Human rights.

Resumen: El presente texto constituye una discusión realizada a partir una investigación que buscó identificar los temas y los contextos tratados en los artículos de la revista Psicología y Sociedad y en los anales de los Encuentros Nacionales de la ABRAPSO, ambos publicados por esa asociación, en el período de 2000 a 2010. A partir los datos relevados, discuto la articulación de los contextos socio-político-cultural y el de las políticas y proyectos sociales, en que el primero revela una gran incidencia y el segundo, una baja incidencia en las publicaciones. Pese a una gran diferencia en la publicación de trabajos que discuten esos contextos, se nota un aumento gradual, de un año a otro, en las producciones que se insieren y que reflexionan acerca del contexto de las políticas y proyectos sociales. Esos datos, por lo tanto, además de otros factores, revelan el compromiso de la Psicología en entrar en los espacios referentes a la construcción de políticas públicas y proyectos sociales con vistas a garantizar la promoción y la defensa de los derechos humanos y de una sociedad digna de ser vivida, o sea, el interés en la construcción del bien común.

Palabras claves: Proyecto social. Política social. Psicología. Derechos humanos.

A Psicologia foi pioneira nos estudos que revelaram a importância das condições subjetivas para a constituição das relações dos seres humanos e da sociedade bem como na articulação da prática de pesquisa e de intervenção social com relação aos grupos, instituições e problemas do cotidiano.

Para compreender um pouco da trajetória da Psicologia (social) no Brasil, tendo como referência a produção acadêmicocientífica nos últimos 10 anos, selecionamos a revista Psicologia e Sociedade e os Anais dos Encontros Nacionais publicados pela ABRAPSO - Associação Brasileira de Psicologia Social - a fim de identificar os temas e os contextos tratados e recobertos nessas produções no período de 2000 a 2010, e será a partir dos dados dessa pesquisa que discutiremos as contribuições da Psicologia (social) na primeira década do século XXI e os possíveis desafios postos à Psicologia na atualidade.

Demarcamos que estamos tratando o campo da Psicologia social como parte integrante do próprio campo da Psicologia, pois é sabido que não existe campo psicológico isolado do campo social, e que a Psicologia social adentra o que chamamos de psicologias. Porém, a principal demarcação aqui reside no fato de, a partir da análise das publicações 
da ABRAPSO, identificarmos que houve uma grande abertura para trabalhos da Psicologia e de outras áreas de saber, muitos deles até contrários àquilo que é entendido como próprio da área da Psicologia social, seja nos sentidos axiológico, epistemológico, metodológico e ontológico, e nos motivos da criação da ABRAPSO. Esta última, portanto, abriga migrações externas e internas à Psicologia, e, além de revelar, nas publicações, o campo chamado psicossocial, revela ainda o campo da própria Psicologia. Destacamos que com isso não estamos excluindo a especificidade da Psicologia social.

A escolha pelas publicações da ABRAPSO se deu pelo fato de essa associação, após sua criação, em 1980, ter se tornado o espaço demarcador de intercâmbio, de posicionamento político e de construção de uma psicologia social crítica.

A criação da ABRAPSO impulsionou a Psicologia social no Brasil, estabeleceu campos de referências para reflexões sobre acontecimentos macroestruturais na relação com o debate científico-acadêmico e permitiu dimensionar um novo olhar para aquilo que vinha sendo pauta da Psicologia, com vistas a essa ciência abarcar novos horizontes e romper a torre de marfim da clínica terapêutica, tomando o homem em sua condição social, inserido em uma sociedade transpassada por questões sociopolítico-econômico-culturais legitimadoras do poder e da exclusão social.

Ao emergir em um contexto demarcado pela égide da ditadura militar, o paradigma de Psicologia social latino-americana assume um caráter político na luta pela conquista dos direitos humanos e de uma sociedade democrática.

Tal fato fez com que as publicações retratassem a Psicologia social e os problemas brasileiros, tais como: violência, movimentos populares, movimentos sociais, Psicologia comunitária, processos grupais, identidade, exploração do trabalho, política e direitos humanos.

A Psicologia social possui percursos articulados com as condições históricas e conjunturais, revelando o compromisso com as demandas sociais e políticas. Entretanto, Freitas conclui, em 1996, que "os temas (se) deslocaram, em certa medida, de uma perspectiva mais abrangente, no que concerne à realidade social, para enfocarem temáticas relativas a situações e contextos particulares e pontuais" (p.176).

É a partir desse panorama que queremos discutir a situação atual da Psicologia (social) revelada nos dados coletados na pesquisa e as (des)articulações de alguns contextos e temas identificados que, necessariamente, deveriam apresentar relações significativas com vistas ao quadro atual da sociedade brasileira e dos desafios postos ao campo da Psicologia que tem sido pauta das diversas entidades da Psicologia e de fóruns de direitos.

\section{Métodos e materiais}

Para realizar os objetivos destacados na introdução, optou-se pela pesquisa de caráter exploratório, porque ela permite a apropriação de uma diversidade de conhecimentos presentes em fontes bibliográficas. Em se tratando de uma pesquisa com essa característica, foi necessário, primeiramente, reunir os fascículos impressos disponíveis e acessar o site oficial da ABRAPSO para completar a seleção do período determinado.

Em seguida, foram realizadas as leituras dos artigos das revistas, na íntegra, e a leitura dos anais dos encontros nacionais; alguns foram lidos na íntegra; de outros, leram-se os resumos expandidos, e de outros, apenas os resumos. Observou-se que os temas seriam de alta diversidade e, portanto, temas que 
partilhavam similaridades foram agrupados. Adotou-se, assim, a compreensão de que tema é o assunto no qual repousa toda a reflexão, ou a proposição que se quer provar, ou ainda o motivo sobre o qual se desenvolve a composição do texto.

Com relação aos temas das publicações dos anais dos encontros nacionais, utilizamos os eixos temáticos dos próprios encontros para ter melhor quantificação desses dados. Essas temáticas, em seguida, foram relacionadas com os seus respectivos contextos.

Na mesma medida, surgiu a necessidade de se definir contexto. No seu uso comum e óbvio, contexto indica "aquilo que está ao redor" e, portanto, o ambiente, ou a situação dentro da qual ocorre algo, onde algo é gerado e que pode ser entendido como aquilo em que iremos focalizar a nossa atenção. Contexto é ainda usualmente compreendido como campo de atuação ou local de atuação, ou ainda como área de atuação.

No desenvolvimento da pesquisa, firmouse o entendimento de contexto como o ambiente social ou situação dentro da qual ocorre algo, o campo de atuação e as circunstâncias envolvidas no delineamento do tema. Procurou-se, nessa definição, incluir enquadres que compartilhavam natureza similar. Assim, foi possível identificar nove contextos considerando o campo do universo pesquisado: socio-políticocultural, clínico e de saúde, educacional, organizacional e do trabalho, comunitário, reflexão epistemológica, políticas e projetos sociais, midiático e das tecnologias de informação e comunicação e cidades, territórios e ambientes.

É importante salientar que, em algumas situações, um mesmo trabalho se referia a mais de um contexto.

Outra identificação e classificação importante referia-se à natureza da reflexão. Dito de outro modo, identificou-se o que se tratava de reflexão teórica elaborada com o amparo de dados de pesquisas, tanto da graduação, de dissertações, teses pós-doutorais e/ou cotejamentos e articulações com outras áreas do conhecimento científico. Em consequência, identificaram-se e separaramse as reflexões teóricas elaboradas sem o amparo de pesquisas. Essas reflexões se caracterizam por ensaios, discussões epistemológicas e conceituais. Assim considerando, temos o seguinte com relação à natureza dos achados: reflexão teórica com pesquisa e reflexão teórica sem pesquisa.

Foi possível, ainda, por meio das leituras, identificar quais os autores mais citados nos textos e nas referências bibliográficas dessas publicações.

Assim sendo, os dados encontrados foram tabulados e agrupados de acordo com os temas e os contextos similares. Simultaneamente, eram tabuladas as reflexões com e sem amparo de dados de pesquisa.

A tabulação e a classificação dos dados possibilitaram construir tabelas e gráficos representativos para os temas e os contextos que se converteram na análise e na interpretação, e é a partir disso que desenvolveremos nossas discussões.

\section{Resultados e discussões}

Destacamos todo o desenvolvimento metodológico da pesquisa para que possamos entender como se deu esse processo e como encontramos tais resultados. Entretanto, não focarei todos os resultados nessas discussões, apenas a (des)articulação dos contextos socio-político-cultural e das políticas e projetos sociais.

Ao longo do período considerado, 2000- 
2010, foram encontrados e trabalhados 33 números da revista Psicologia e Sociedade, composta por 11 volumes, totalizando 418 artigos, assim dispostos: do ano 2000 a 2003, há publicação de dois números por ano, contando com os volumes de 12 a 15; a partir de 2004 até 2010, há o aumento de um número por ano, com a publicação de três números por ano, indo do volume 16 ao 22. Há situações de exceção que contam com a publicação de números especiais que são ou temáticos ou de homenagem nos anos 2007 (dois números especiais), 2008 (um número) e 2009 (um número).

Com relação aos anais dos Encontros Nacionais, trabalhou-se com 2.047 publicações dispostas no ano 2001, que tinha como tema do encontro Psicologia e Transformação da Realidade Brasileira: Desafios e Perspectivas para a ABRAPSO 21 Anos Depois; de 2003, que tinha como tema Estratégias de Intervenção do Presente: a Psicologia Social no Contemporâneo; de 2007, com o tema Diálogos em Psicologia Social: Epistemológicos, Metodológicos, Éticos, Políticos, Estéticos e Políticas Públicas, e de 2009, cujo tema era Psicologia Social e Políticas de Existência: Fronteiras e Conflitos.

Os contextos identificados nos artigos da revista, somados aos dos anais dos encontros, considerando todo o período, permitiram ser categorizados, quantificados e constituíram o seguinte no que se refere à incidência das produções: socio-político-cultural (26\%), clínico e de saúde (20\%), educacional (19\%), organizacional e do trabalho (9\%), comunitário $(7 \%)$, reflexão epistemológica (7\%), políticas e projetos sociais (5\%), midiático e das tecnologias de informação e comunicação (5\%) e cidades, territórios e ambientes (2\%).

Apesar de todos os contextos serem importantes, irei destacar dois que revelam um material significativo para pensarmos sobre a Psicologia em seu panorama atual, em que as políticas públicas ou a sua ausência têm sido pauta constante de discussões: o contexto socio-político-cultural e o contexto das políticas e projetos sociais.

O contexto socio-político-cultural acolhe trabalhos que refletem acerca da garantia de direitos humanos, dos processos de democratização, da política e do político, da etnia e do racismo, dos grupos e movimentos sociais, da violência física e simbólica, das questões de gênero, estudos culturais e sobre a cultura, religião e o simbólico, e há reflexões acerca da conjuntura política e econômica do País.

O contexto das políticas e projetos sociais trata das experiências e reflexões relacionadas às políticas públicas e aos projetos sociais, à participação social, ao controle social e à construção dessas políticas com experiências em conferências, sindicatos, Conselhos e fóruns de direitos humanos, visando à construção da democracia e de políticas direcionadas aos direitos dos cidadãos.

Percebe-se que o contexto socio-políticocultural possui a maior incidência de publicações, atingindo $26 \%$, enquanto o contexto das políticas e projetos sociais possui quase a menor incidência de publicações, contando com apenas 5\%.

É sabido, ao menos na configuração atual de nossa sociedade, que, para a construção de uma sociedade mais justa e para o desenvolvimento do panorama sócio-políticocultural, a construção de políticas públicas faz-se inevitável e imprescindível.

As políticas públicas, tanto sociais, educacionais, de saúde, ou outras, têm sido pauta constante das diversas entidades da Psicologia, pois são elas que garantem os direitos dos cidadãos, sejam eles idosos, adultos, adolescentes ou crianças, 
Pereira (2007) comenta que o fato de a Psicologia adentrar o campo público é uma forma contrahegemônica de fazer Psicologia. reconhecendo-os como sujeitos de direitos. Entretanto, as publicações revelam que ainda há uma baixa incidência de produções acerca das políticas públicas e dos projetos sociais, uma vez que o panorama socio-políticocultural atual vem sendo intensamente considerado e necessita de profundas e drásticas mudanças, e é por meio da construção dessas políticas que se pode pensar em mudanças na sociedade e em que a conquista, a promoção, a proteção, a defesa e a garantia dos direitos humanos serão legitimados.

Tanto nos artigos da revista como nos anais dos encontros, o contexto socio-políticocultural está presente desde o início do período estudado, e sua produção tem grande incidência, sendo destaque das produções em todo ano, a saber: na revista: 65\% em 2000, 28\% em 2001, 41\% em 2002, $53 \%$ em 2003, 26\% em 2004, 23\% em 2005, 43\% em 2006, 35\% em 2007, 17\% em 2008 e $8 \%$ em 2009 (isso pelo fato de, nesse ano, ter havido duas publicações especiais, uma de homenagem a Silvia Lane e outra temática de psicanálise, o que fez com que outros contextos apresentassem maior incidência), e 30\% em 2010; nos encontros nacionais: 16\% em 2001, 25\% em 2003, 30\% em 2007 e $23 \%$ em 2009.

Com relação ao contexto das políticas e projetos sociais, aparecem publicações na revista apenas a partir de 2004; já nos anais dos encontros nacionais, as publicações se fazem presentes desde 2001. Essas produções apresentam, em alguns anos, aumento gradativo de um ano para outro, apesar de em alguns anos não aparecerem ou terem baixa incidência: na revista: $12 \% \mathrm{em}$ 2004, 13\% em 2005, 7\% em 2006, em 2007 não apresenta produções, 17\% em 2008, 7 \% em 2009, e, em 2010, também não apresenta produções acerca desse contexto; nos encontros nacionais: $3 \%$ em 2001, 5\% em 2003, 5\% em 2007 e 2\% em 2009.

Apesar da timidez ainda das publicações referentes ao contexto das políticas, dos projetos sociais e das políticas públicas, percebe-se que o aumento do interesse acerca dessas produções revela que a Psicologia tem adentrado e se interessado pelos espaços de construção dessas políticas e do exercício do controle social, com vistas a garantir a condição de cidadão dos sujeitos humanos. Pereira (2007) comenta que o fato de a Psicologia adentrar o campo público é uma forma contra-hegemônica de fazer Psicologia. De acordo com Carmo (2001), o compromisso dos psicólogos com as políticas públicas tem a ver com sua inserção social como cidadãos.

Esse interesse ainda é notado na $2^{a}$ Mostra Nacional de Práticas em Psicologia, quando, 12 anos após o acontecimento da primeira, o tema é Compromisso com a Construção do Bem Comum. Para discutir como fazermos isso, contamos com a presença de Pedro Pontual, ligado à Secretaria-Geral da Presidência da República no Departamento de Participação Social, Paulo Vanuchi, principal responsável pelo Plano Nacional de Direitos Humanos, Marcus Vinícius de Oliveira, que discutiu a posição do Sistema Conselhos de Psicologia acerca do direito à verdade, e de outras figuras importantes que partilham e lutam pela conquista de um país mais justo, além de outros temas que compuseram as mesas e as diversas discussões que tratavam do bem comum, da conquista de direitos humanos e outros direitos, de controle social, de gestão pública e outros. Em uma sala onde foi projetado um vídeo sobre os direitos humanos, cujo título era Direitos Humanos, Nossos Direitos, que fazia uma homenagem a Vladimir Herzog, aqueles que por ela passaram não saíram sem ter despertadas uma inquietação e indignação frente às injustiças e violências cometidas neste país. 
revelou, portanto, o imprescindível e necessário compromisso que a Psicologia, em seu panorama atual, tem assumido com as políticas públicas, os projetos sociais, os direitos humanos, ou seja, o compromisso com o bem comum para a construção uma sociedade mais justa e igualitária.

É possível ainda pensar que o aumento do interesse de publicações no contexto das políticas e dos projetos sociais seja reflexo dos Seminários de Psicologia e de Políticas Públicas realizados pelo Sistema Conselhos de Psicologia, o qual teve seu primeiro encontro em nível nacional, em 2001, organizado pelo Conselho Federal de Psicologia. É sabido que um encontro é realizado a partir da percepção de uma demanda que já se faz concreta, porém, a influência desses seminários, onde se discute a relação da Psicologia com as políticas públicas, é imprescindível na determinação dos caminhos da Psicologia percorridos nessa esfera.

Ainda a criação do CREPOP (Centro de Referência Técnica em Psicologia e Políticas Públicas), em 2006, é reveladora do interesse e da demanda que têm sido apresentados à Psicologia para atuar no âmbito das políticas públicas, principalmente no que se refere à redução da desigualdade social.

A premiação organizada pelo Conselho Federal de Psicologia em homenagem ao professor César Ades, que foi um dos maiores psicólogos do Brasil, demarca a preocupação de Ades acerca das contribuições da Psicologia para a construção do futuro da nossa sociedade. O interesse da Psicologia, em seu panorama atual, na inserção em espaços de construção das políticas públicas, dos projetos sociais e dos direitos humanos é imprescindível para a transformação do panorama socio-político-cultural e para garantir um futuro digno, mais justo e igualitário em nossa sociedade. Para isso, destaca Pereira que é preciso que a política da Psicologia seja uma política pública. Acredito que a preocupação de Ades com o futuro da sociedade apontava esse caminho.

Conforme destaca Oliveira (2007), os espaços aos quais a Psicologia tem tido acesso para atuar nas políticas públicas se referem às ações do Estado, que visam à redução da desigualdade social. Atuar nesses espaços com vistas à execução desses objetivos é contribuir para a construção do futuro da nossa sociedade.

Apesar de as publicações acerca das políticas públicas e projetos sociais ainda serem tímidas no sentido de baixa produção, até pelo fato de o interesse do Estado em investir nessas políticas ter sido recente, percebese que as pautas e as problemáticas que têm permeado o campo da Psicologia nos últimos anos têm perpassado por questões que revelam o interesse com o compromisso e com a construção do bem comum, com a construção de políticas públicas e projetos sociais, com a participação social, o controle social e com a conquista e a defesa dos direitos humanos.

\section{Considerações finais}

Apesar da (des)articulação e do distanciamento das produções acerca da estrutura sociopolítico-cultural, que, no panorama atual, está marcada pela injustiça e pela exclusão social, com relação à incidência das produções no âmbito das políticas, projetos sociais e políticas públicas, o interesse e o envolvimento daqueles profissionais que visam à construção de uma Psicologia compromissada com o bem comum tem sido orientada para o engajamento em espaços em que se constroem e se garantem os direitos humanos, as políticas públicas e os projetos sociais, na busca de uma sociedade mais justa e igualitária onde todos possam ter uma vida digna de ser vivida. Conforme destaca 
Carvalho (2001), nosso papel de psicólogos é contribuir para que haja políticas públicas que tornem as pessoas cada vez mais cidadãs, pessoas que desejem construir a própria história.

A emblemática da construção de políticas públicas se coloca diante da Psicologia como uma questão imprescindível, pois, sendo essa a ciência que estuda a subjetividade humana, cabe a ela, juntamente a outras áreas de saber, responsabilizar-se pela construção das políticas públicas e do bem comum a fim de garantir territórios de existência que possibilitem a constituição de subjetividades singularizadas.

\section{Vinicius Furlan}

Discente do curso de Psicologia da Universidade Metodista de Piracicaba, Piracicaba - SP - Brasil.

E-mail:vcfurlan@unimep.br

\section{Mariá Aparecida Pelissari}

Doutora em Psicologia Social pela Pontifícia Universidade Católica de São

Paulo e docente da Universidade Metodista de Piracicaba, Piracicaba - SP - Brasil.

E-mail: mapeliss@unimep.br

Endereço para envio de correspondência:

Rua Francisco Jorge de Moraes, 153. CEP: 13515-000. Charqueada, SP.

Carmo, M. do. (2001). Políticas públicas como um desafio para os psicólogos. In Relatório do I Seminário Nacional de Psicologia e Políticas Públicas. I Seminário Nacional de Psicologia e Políticas Públicas. Salvador, BA: Conselho Federal de Psicologia

Carvalho, M. C. (2001). Políticas públicas como um desafio para os psicólogos. In Relatório do I Seminário Nacional de Psicologia e Políticas Públicas. I Seminário Nacional de Psicologia e Políticas Públicas. Salvador, BA: Conselho Federal de Psicologia.

Freitas. M. F. Q de. (1996). Psicologia na comunidade, psicologia da comunidade, e psicologia (social) comunitária - práticas da psicologia em comunidades das décadas de 60 a 90 no Brasil.
In R. H. de F. Campos (Org.), Psicologia social comunitária: da solidariedade à autonomia. Petrópolis, RJ: Vozes.

Oliveira, M. V. de. (2007). Políticas públicas e psicologia: potencialidades e desafios dessa relação. In Relatório do IV Seminário Nacional de Psicologia e Políticas Públicas. IV Seminário Nacional de Psicologia e Políticas Públicas. Maceió: CFP; ULAPSI.

Pereira, E. H. P. (2007). Políticas públicas e psicologia: potencialidades e desafios dessa relação. In Relatório do IV Seminário Nacional de Psicologia e Políticas Públicas. IV Seminário Nacional de Psicologia e Políticas Públicas. Maceió: CFP; ULAPSI. 